\title{
HPV infection and p53 and p16 expression in esophageal cancer: are they prognostic factors?
}

\author{
Allini Mafra da Costa ${ }^{1,2^{*}}$, José Humberto Tavares Guerreiro Fregnani ${ }^{1}$, Paula Roberta Aguiar Pastrez ${ }^{1,3}$, \\ Vânia Sammartino Mariano 1,3, Estela Maria Silva ${ }^{1,3}$, Cristovam Scapulatempo Neto ${ }^{1}$, Denise Peixoto Guimarães ${ }^{3,4}$, \\ Luisa Lina Villa ${ }^{5,6}$, Laura Sichero ${ }^{5}$, Kari Juhani Syrjanen ${ }^{1,3,7}$ and Adhemar Longatto-Filho ${ }^{1,3,8,9,10}$
}

\begin{abstract}
Background: Esophageal squamous cell carcinoma (ESCC) is a highly lethal malignant tumor. Currently, Human papillomavirus (HPV) is suggested as a potential risk factor for esophageal cancer (EC) in addition to the classic risk factors, alcohol and tobacco, but this hypothesis still remains contradictory. We sought to investigate wether HPV and well-known biomarkers (p16 and p53) and patient-related factors that may have impact on survival of ESCC.

Methods: We conducted a prospective cohort study. By using multiplex PCR, we determined the prevalence of high risk HPV in ESCC, and evaluated the immunohistochemical expression of p16 and p53, molecular markers related to esophageal carcinogenesis in order to verify the potential influence of these variables in patients's survival. Survival rates were estimated using Kaplan-Meier methods. A multivariate confirmatory model was performed using Cox proportional hazards regression.

Results: Twelve (13.8\%) of 87 patients were HPV-DNA positive. Positive reactions of p16 and p53 were 10.7\% and $68.6 \%$, respectively. Kaplan-Meier analysis indicated that men $(p=0.025)$ had poor specific-cancer survival and a shorter progression-free survival $(p=0.050)$ as compared to women; III or IV clinical stage $(p<0.019)$ had poor specific-cancer survival and a shorter progression-free survival $(p<0.001)$ compared to I and II clinical stage; not submitted to surgery $(<0.001)$ and not submitted to chemoradiotherapy $(p=0.039)$ had a poor specific-cancer survival, as well. The multivariate analysis showed that HPV, p16 and p53 status are not predictive parameters of progression-free and specific-cancer survival.
\end{abstract}

Conclusion: HPV infection and p53 and p16 expression are not prognostic factors in ESCC.

Keywords: Human Papillomavirus, Esophageal cancer, Survival

\section{Background}

Presently, esophageal cancer (EC) is regarded as an important public health problem worldwide, being considered the eighth most common type of cancer and the sixth leading cause of cancer death according to estimates by GLOBOCAN 2012 [1].

\footnotetext{
* Correspondence: mafra.allini@gmail.com

${ }^{1}$ Teaching and Research Institute, Barretos Cancer Hospital - Pius XII

Foundation, Rua Antenor Duarte Vilela, 1331, Dr. Paulo Prata, Barretos, São

Paulo 14784-400, Brazil

${ }^{2}$ Cancer Registry, Barretos Cancer Hospital - Pius XII Foundation, São Paulo, Brazil

Full list of author information is available at the end of the article
}

Despite recent advances in multidisciplinary treatments, including radical surgical resection, chemotherapy and radiotherapy, the 5-year survival rate of patients with esophageal squamous cell carcinoma (ESCC) remains being less than $30 \%$, and this is due mainly to atypical early symptoms, middle-to-late stage diagnosis, low treatment remission rates and high local recurrence rates, requiring the identification of a suitable biomarker to predict their long-term survival $[2,3]$.

Recently, evidence suggests that human papillomavirus (HPV) may play an important role in ESCC development; a number of studies in this area has increased steadily, as evidenced in several reviews [4-9]. First descriptions of 
oral lesions associated with HPV were preceded by reports that suggested the involvement of viruses in the development of benign [10] and malignant [11] lesions of the squamous epithelium of the esophagus. These initial observations were based on the report of morphological similarities between HPV lesions in the genital tract (warts) and esophageal papillomas [10, 11].

The first report that demonstrated the presence of HPV in ESCC occurred more than 30 years [10]; however, its prevalence is significantly variable among different geographical regions, and its role in carcinogenesis is still a matter of debate. Although the number of studies and interest in the subject has increased in recent years, literature is still controversial [12]. Data accumulated reflects a trend linking HPV infection and EC in high risk areas, whereas in low-risk areas such association was not evident [13].

The molecular genetic background of ESCC, mainly researches on protein alterations, has been widely studied and may assist in the prognosis of patients [14]. Proteins such as p53, p16 and others have been considered as prognostic factors for ESCC [15].

The differential expression of the tumor suppressor protein p53 is one of the commonest abnormality in several cancer types, including EC, and its mutation is mainly related to cell invasion and metastasis, as well as being related to advanced stages of the disease [14]. These mutations can lead to an increase in expression of p53, which accumulates in the nuclei and can be detected by immunohistochemistry (IHC) methods $[16,17]$. The p16 protein expression is frequently used as a surrogate marker for HPV infection, and was shown as a marker for responder and better prognosis among head and neck squamous cell carcinoma patients who underwent radiotherapy [18]. Similarly, high p16 expression supposedly correlates with favorable prognosis in esophageal squamous cell carcinoma as well $[19,20]$, although data are still limited and variable [16, 18-23].

A retrospective cohort study with 136 ESCC patients has showed that p53 overexpression was associated with poor prognosis in these patients and a significantly independent predictor of poor overall survival [16]. However, this prognostic role of p53 overexpression in ESCC remained unclear [16].

Necessary strategies to improve prognosis and survival rates in patients with EC require early diagnosis and treatment, which rely on studying and exploring factors that influence the prognosis of such neoplasia.

This study aimed to evaluate the correlation of HPV infection and the expression of p53 and p16 with clinicopathologic factors, and whether they are ESCC prognostic factors for cancer progression (survival).

\section{Methods}

This was a prospective cohort study. Briefly, the patients of both genders, aged above 18 years, admitted to the
Barretos Cancer Hospital, with histopathological confirmation of ESCC, clinical indication for endoscopy and no previous treatment for cancer were included. Medical records were available to obtain clinical and follow-up data.

\section{Sample collection, HPV detection and characterization}

The procedure for conducting the Digestive Endoscopy followed the routine of the Department of Endoscopy at Barretos Cancer Hospital using sedation, flexible video endoscopes (Olympus 180, Japan; Fuginon 4400, Japan) and Single-Use Radial Jaw 4 Biopsy Forceps (Boston Scientific Corporation, Natick, MA). Biological samples were collected from tumors tissues, fixed in $10 \%$ buffered formalin and embedded in paraffin. Slides were routinely stained with Hematoxylin-Eosin.

HPV DNA, obtainened by organic extraction [24], was measured in all samples using type-specific PCR bead-based multiplex genotyping (TS-MPG) assays that combine multiplex polymerase chain reaction (PCR) and bead based Luminex technology (Luminex Corp., Austin, TX, USA), as described by Pastrez et al. and da Costa et al. [25, 26].

A primer set targeting the $\beta$-globin gene were included as a positive control for the quality of the template DNA and the mix without sample was a negative control. HPV multiplex PCR was performed with QIAGEN Multiplex PCR Kit (Qiagen, Dusseldorf, Germany), according to manufacturer's instructions, and the details of the reaction can be seen in Pastrez et al. [25] methodology.

For the hybridization assay, the mean fluorescence intensity (MFI) values were obtained when no PCR product was added to the mixture of hybridization was considered as background, for each probe, was performed according to Schmitt et al. (2006) [27]. The cutoff was calculated by adding 5 MFI for $1.1 \mathrm{X}$ the value of median found, and values higher than 20 MFI was considered positive.

\section{Immunohistochemistry}

The immunohistochemistry expression of p16 and p53 proteins were analyzed in automated system (Ventana Benchmark ULTRA, CA, USA) using a primary antibody against p16 (monoclonal mouse anti-human p16INK4A protein, Clone E6H4TM, ready for use, Roche Brazil) and p53 (monoclonal mouse anti-human p53 protein, Clone DO-7, dilution 1:1200, Cell Marque, Rocklin, CA, USA). The scores for analysis oh the proteins and details can be seen in a former study recently published [25].

\section{Statistical analysis}

Survival rates were estimated in months, and survival was defined as the period from the date of diagnosis to the date of death or the date at which information was 
last obtained from the patient. For the analysis, the event of interest was death related to cancer to specific-cancer survival and the locoregional recurrence, progression or metastasis to progression-free survival. Cases that were alive or dead from other causes were censored to specific-cancer survival and without locoregional recurrence, progression or metastasis to progression-free survival. Such information was obtained through direct consultation to the death certificate or medical records. Multiple confirmatory models were used to check whether HPV, p53 and p16 status were related to prognosis of ESCC. Multivariable Cox proportional hazards regression models was used to estimate hazard ratios (HR) and 95\% confidence intervals (CI) with adjustment for sex, clinical stage and treatment. Fisher exact test was used to association analysis. For tabulation and statistical analysis we used IBM $^{\bullet}$ SPSS $^{\bullet}$ Statistics 20.0.1 software for Windows (IBM Corporation, Route 100, Somers NY 10589). The level of statistical significance was set at 0.05 for all analysis.

\section{Results}

During the period between February 2013 and August 2014, 123 patients with ESCC were enrolled in this study. Age ranged from 41 to 92 years (mean $=60.9$ years, $\mathrm{SD}=10.3$ years; median $=61$ years). Patients characteristics are described in Table 1; HPV, p53 and p16 status versus patients characteristics are depicted in Table 2.

Kaplan-Meier analysis indicated that ESCC male patients had a poor specific-cancer survival $(p=0.025)$ and a shorter progression-free survival $(p=0.050)$; III or IV clinical stage $(p<0.019)$ had a poor specific-cancer survival and a shorter progression-free survival $(p<0.001)$; not submitted to surgery $(<0.001)$ and not submitted to chemoradiotherapy (CTR) $(p=0.039)$ had a poor specific-cancer survival. Those patients with disease progression or metastasis $(<0.001)$ had a poor specificcancer survival (Table 3). The distribution of cases according to patients' characteristics and survival rates are shown with more details in Table 3 and the survival curves shown in Fig. 1.

In the multivariate analysis, using a confirmatory model, HPV, p16 and p53 did not show any prediction value related to the progression-free and specific-cancer survival. Results of the multivariable Cox regression analysis are shown in Table 4.

\section{Discussion}

Esophageal cancer is an extremely aggressive disease, which is usually diagnosed at an advanced stage, due mainly to the lack of specific initial symptoms. Consequently, EC infiltrates organs and metastasizes straightforwardly, resulting in poor prognosis and 5year survival of $15-34 \%$ [28-30]. In cases of advanced
Table 1 Patients' characteristics

\begin{tabular}{|c|c|c|c|}
\hline \multirow[t]{2}{*}{ Variable } & \multirow[t]{2}{*}{ Category } & \multirow[b]{2}{*}{$\mathrm{n}$} & \multirow[b]{2}{*}{$\%$} \\
\hline & & & \\
\hline \multirow[t]{2}{*}{ Sex } & Female & 23 & 18.7 \\
\hline & Male & 100 & 81.3 \\
\hline \multirow[t]{2}{*}{ Age at diagnosis } & $\leq 60$ years old & 60 & 48.8 \\
\hline & $>60$ years old & 63 & 51.2 \\
\hline \multirow[t]{2}{*}{ Alcohol consumption } & $\leq 20$ years & 24 & 19.5 \\
\hline & $>20$ years & 99 & 80.5 \\
\hline \multirow[t]{2}{*}{ Tobacco consumption } & $\leq 20$ years & 26 & 21.1 \\
\hline & $>20$ years & 97 & 78.9 \\
\hline \multirow[t]{4}{*}{ Clinical stage ${ }^{a}$} & । & 3 & 2.6 \\
\hline & $\|$ & 26 & 22.8 \\
\hline & III & 58 & 50.9 \\
\hline & IV & 27 & 23.7 \\
\hline \multirow[t]{3}{*}{ Histological grade * } & Well differentiated & 14 & 11.6 \\
\hline & Moderately differentiated & 73 & 60.3 \\
\hline & Poorly differentiated & 34 & 28.1 \\
\hline \multirow[t]{2}{*}{ Surgery } & No & 102 & 82.9 \\
\hline & Yes & 21 & 17.1 \\
\hline \multirow[t]{2}{*}{ Radiotherapy } & No & 51 & 41.5 \\
\hline & Yes & 72 & 58.5 \\
\hline \multirow[t]{2}{*}{ Chemotherapy } & No & 45 & 36.6 \\
\hline & Yes & 78 & 63.4 \\
\hline \multirow[t]{2}{*}{ Progression } & No & 84 & 68.3 \\
\hline & Yes & 39 & 31.7 \\
\hline \multirow[t]{2}{*}{ Status } & Death by cancer & 93 & 75.6 \\
\hline & Alive & 30 & 24.4 \\
\hline \multirow[t]{2}{*}{$\mathrm{HPV}^{\mathrm{a}}$} & Negative & 75 & 86.2 \\
\hline & Positive & 12 & 13.8 \\
\hline \multirow[t]{2}{*}{$p 16^{a}$} & Negative & 108 & 89.3 \\
\hline & Positive & 13 & 10.7 \\
\hline \multirow[t]{2}{*}{$\mathrm{p} 53^{\mathrm{a}}$} & Negative & 37 & 31.4 \\
\hline & Positive & 81 & 68.6 \\
\hline
\end{tabular}

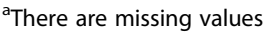

disease, it is well established that standard treatment is CRT followed by surgery [31], which leads to downgrade the tumor stage and increase the complete resection rate [2]. However, the cure rate and survival of these patients is still low, requiring other methods which may assist in predicting survival and identification of potential responders to a given therapy.

Until now, published data demonstrate that clinichistopathological factors, molecular biomarkers, and HPV infection are, possibly, predictive variables for neoadjuvant therapy [2,31]. In head and neck cancer, HPV-positive patients have a better response to CRT 
Table 2 HPV, p53 and p16 status versus patients' characteristics

\begin{tabular}{|c|c|c|c|c|c|c|c|c|c|}
\hline \multirow[t]{2}{*}{ Treatment } & \multicolumn{2}{|l|}{$\mathrm{HPV}^{\mathrm{a}}$} & \multirow[t]{2}{*}{$p$} & \multicolumn{2}{|l|}{$\mathrm{p} 16^{\mathrm{a}}$} & \multirow[t]{2}{*}{$p$} & \multicolumn{2}{|l|}{$\mathrm{p} 53^{\mathrm{a}}$} & \multirow[t]{2}{*}{$p$} \\
\hline & Negative & Positive & & Negative & Positive & & Negative & Positive & \\
\hline \multicolumn{10}{|l|}{ Sex } \\
\hline Female & $16(21.3)$ & $3(25.0)$ & 0.720 & $18(16.7)$ & $5(38.5)$ & 0.071 & $6(16.2)$ & $17(21.0)$ & 0.624 \\
\hline Male & $59(78.7)$ & $9(75.0)$ & & $90(83.3)$ & $8(61.5)$ & & 31 (83.8) & $64(79.0)$ & \\
\hline \multicolumn{10}{|l|}{ Age at diagnosis } \\
\hline$\leq 60$ years old & $39(52.0)$ & $7(58.3)$ & 0.763 & $51(47.2)$ & $7(53.8)$ & 0.772 & $14(37.8)$ & $44(54.3)$ & 0.115 \\
\hline$>60$ years old & $36(48.0)$ & $5(41.7)$ & & $57(52.8)$ & $6(46.2)$ & & $23(62.2)$ & 37 (45.7) & \\
\hline \multicolumn{10}{|l|}{ Alcohol consumption } \\
\hline$\leq 20$ years & $19(25.3)$ & $2(16.7)$ & 0.722 & $21(19.4)$ & $3(23.1)$ & 0.720 & $7(18.9)$ & $17(21.0)$ & 0.813 \\
\hline$>20$ years & $56(74.7)$ & $10(83.3)$ & & 87 (80.6) & $10(76.9)$ & & $30(81.1)$ & $64(79.0)$ & \\
\hline \multicolumn{10}{|l|}{ Tobacco consumption } \\
\hline$\leq 20$ years & $14(18.7)$ & $5(41.7)$ & 0.125 & $25(23.1)$ & $1(7.7)$ & 0.295 & $8(21.6)$ & $18(22.2)$ & 0.572 \\
\hline$>20$ years & $61(81.3)$ & $7(58.3)$ & & $83(76.9)$ & $12(92.3)$ & & $29(78.4)$ & $63(77.8)$ & \\
\hline \multicolumn{10}{|l|}{ Clinical stage } \\
\hline | or || & $21(29.2)$ & $2(16.7)$ & 0.497 & $26(26.0)$ & $3(23.1)$ & 1.000 & $5(14.3)$ & $23(30.3)$ & 0.099 \\
\hline III or IV & $51(70.8)$ & $10(83.3)$ & & $74(74.0)$ & $10(76.9)$ & & $30(85.7)$ & $53(69.7)$ & \\
\hline \multicolumn{10}{|l|}{ Histological grade } \\
\hline Well differentiated & $11(15.1)$ & $0(0.0)$ & 0.442 & $13(12.3)$ & $1(7.7)$ & 0.912 & $7(18.9)$ & $7(8.9)$ & 0.264 \\
\hline Moderately differentiated & $42(57.5)$ & $9(75.0)$ & & $62(58.5)$ & $9(69.2)$ & & $19(51.4)$ & $49(62.0)$ & \\
\hline Poorly differentiated & $20(27.4)$ & $3(25.0)$ & & $31(29.2)$ & $3(23.1)$ & & $11(29.7)$ & $23(29.1)$ & \\
\hline \multicolumn{10}{|l|}{ Surgery } \\
\hline No & $58(77.3)$ & $12(100.0)$ & 0.112 & $95(88.0)$ & $7(53.8)$ & 0.006 & $31(83.8)$ & $69(85.2)$ & 1.000 \\
\hline Yes & $17(22.7)$ & $0(0.0)$ & & $13(12.0)$ & $6(46.2)$ & & $6(16.2)$ & $12(14.8)$ & \\
\hline \multicolumn{10}{|l|}{ Chemoradiotherapy } \\
\hline No & $18(24.0)$ & $0(0.0)$ & 0.140 & $24(22.2)$ & $2(15.4)$ & 0.803 & $7(18.9)$ & $17(21.0)$ & 0.871 \\
\hline Chemo or Radio & $25(33.3)$ & $6(50.0)$ & & $38(35.2)$ & $4(30.8)$ & & $12(32.4)$ & $29(35.8)$ & \\
\hline Chemo and Radio & $32(42.7)$ & $6(50.0)$ & & $46(42.6)$ & $7(53.8)$ & & $18(48.6)$ & $35(43.2)$ & \\
\hline \multicolumn{10}{|l|}{ HPV } \\
\hline Negative & - & - & - & $65(85.5)$ & $9(90.0)$ & 1.000 & 24 (88.9) & 47 (83.9) & 0.743 \\
\hline Positive & - & - & & $11(14.5)$ & $1(10.0)$ & & $3(11.1)$ & $9(16.1)$ & \\
\hline \multicolumn{10}{|l|}{$\mathrm{p} 16^{\mathrm{a}}$} \\
\hline Negative & 65 (87.8) & 11 (91.7) & 1.000 & - & - & - & 34 (91.9) & 72 (88.9) & 0.751 \\
\hline Positive & $9(12.2)$ & $1(8.3)$ & & - & - & & $3(8.1)$ & $9(11.1)$ & \\
\hline \multicolumn{10}{|l|}{$p 53^{a}$} \\
\hline Negative & 24 (33.8) & $3(25.0)$ & 0.743 & 34 (91.9) & 72 (88.9) & 0.751 & - & - & - \\
\hline Positive & $47(66.2)$ & $9(75.0)$ & & $3(8.1)$ & $9(11.1)$ & & - & - & \\
\hline
\end{tabular}

${ }^{\text {a }}$ There are missing values

Entries in boldface are significantly different

and a higher survival rate in relation to HPV-negative cancers [32-34]. Due to the fact that the esophagus can also be infected with these viruses, a similar association and clinical characteristics [20] are supposed. However, the impact of HPV infection on the prognosis of ESCC is still uncertain [2,35]. In addition, the recent advances in HPV vaccination can believed to improve the reduction of HPV-related tumors in nongynecological cancers, which is a optimistic scenario to be proved in near future [36].

Previous work of our study group showed a rate of high-risk HPV infection in esophageal tumor samples $(13.8 \%)[25,26]$, which led us to investigate whether this event could influence the survival of our patients. 
Table 3 Survival rates according to clinical and pathological data

\begin{tabular}{|c|c|c|c|c|c|c|}
\hline \multirow[t]{2}{*}{ Variable } & \multicolumn{3}{|c|}{ Progression-free survival } & \multicolumn{3}{|c|}{ Specific survival } \\
\hline & Total events & One-year & $p$-value & Total events & One-year & $p$-value \\
\hline \multicolumn{7}{|l|}{ Sex } \\
\hline Female & 4 & 86.7 & 0.050 & 14 & 72.3 & 0.025 \\
\hline Male & 35 & 63.3 & & 79 & 49.8 & \\
\hline \multicolumn{7}{|l|}{ Age at diagnosis } \\
\hline$\leq 60$ years old & 18 & 73.3 & 0.553 & 45 & 54.9 & 0.266 \\
\hline$>60$ years old & 21 & 63.0 & & 48 & 53.2 & \\
\hline \multicolumn{7}{|l|}{ Alcohol consumption } \\
\hline$\leq 20$ years & 5 & 74.6 & 0.218 & 16 & 62.0 & 0.301 \\
\hline$>20$ years & 34 & 66.9 & & 77 & 52.0 & \\
\hline \multicolumn{7}{|l|}{ Tobacco consumption } \\
\hline$\leq 20$ years & 11 & 51.3 & 0.158 & 19 & 49.0 & 0.796 \\
\hline$>20$ years & 28 & 73.1 & & 74 & 55.3 & \\
\hline \multicolumn{7}{|l|}{ Clinical stage ${ }^{a}$} \\
\hline | or || & 6 & 91.2 & 0.019 & 13 & 78.6 & $<0.001$ \\
\hline III or IV & 32 & 57.9 & & 73 & 44.2 & \\
\hline \multicolumn{7}{|l|}{ Histological grade ${ }^{a}$} \\
\hline Well differentiated & 4 & 76.2 & 0.170 & 10 & 63.5 & 0.426 \\
\hline Moderately differentiated & 18 & 72.4 & & 55 & 48.8 & \\
\hline Poorly differentiated & 15 & 57.4 & & 26 & 61.4 & \\
\hline \multicolumn{7}{|l|}{ Surgery } \\
\hline No & 32 & 65.8 & 0.486 & 84 & 47.5 & $<0.001$ \\
\hline Yes & 7 & 80.0 & & 9 & 85.4 & \\
\hline \multicolumn{7}{|l|}{ Chemoradiotherapy } \\
\hline No & 8 & 72.4 & 0.731 & 24 & 34.6 & 0.039 \\
\hline Chemo or Radio & 15 & 62.3 & & 36 & 47.7 & \\
\hline Chemo and Radio & 16 & 72.9 & & 33 & 69.1 & \\
\hline \multicolumn{7}{|l|}{$H P V^{a}$} \\
\hline Negative & 23 & 69.3 & 0.885 & 56 & 52.6 & 0.093 \\
\hline Positive & 3 & 71.4 & & 11 & 31.3 & \\
\hline \multicolumn{7}{|l|}{ p16 } \\
\hline Negative & 35 & 66.9 & 0.956 & 84 & 52.4 & 0.739 \\
\hline Positive & 4 & 75.2 & & 9 & 60.6 & \\
\hline \multicolumn{7}{|l|}{$\mathrm{p} 53^{\mathrm{a}}$} \\
\hline Negative & 12 & 66.3 & 0.892 & 27 & 51.4 & 0.584 \\
\hline Positive & 26 & 67.0 & & 63 & 54.9 & \\
\hline
\end{tabular}

${ }^{\text {a }}$ There are missing values

Entries in boldface are significantly different

However, the current study demonstrated that HPV infection showed no impact on the survival of patients with ESCC and similar results were found in other studies $[2,35,37,38]$.

Hippelainen et al. (1993), e.g., detected HPV in $11 \%$ of the esophageal tumors analyzed but the infection was not associated with higher survival rate [38]. Dreilich et al. (2006) detected only HPV 16 in their esophageal samples and showed no influence of virus in survival or improvement of therapy response [35]. Liu et al. (2010) demonstrated that infection of HPV 16 and p53 protein expression were not correlated with survival during the 5-year follow-up period in ESCC [37]. Herbster et al. (2012) found mostly HPV 16 positive in esophageal 

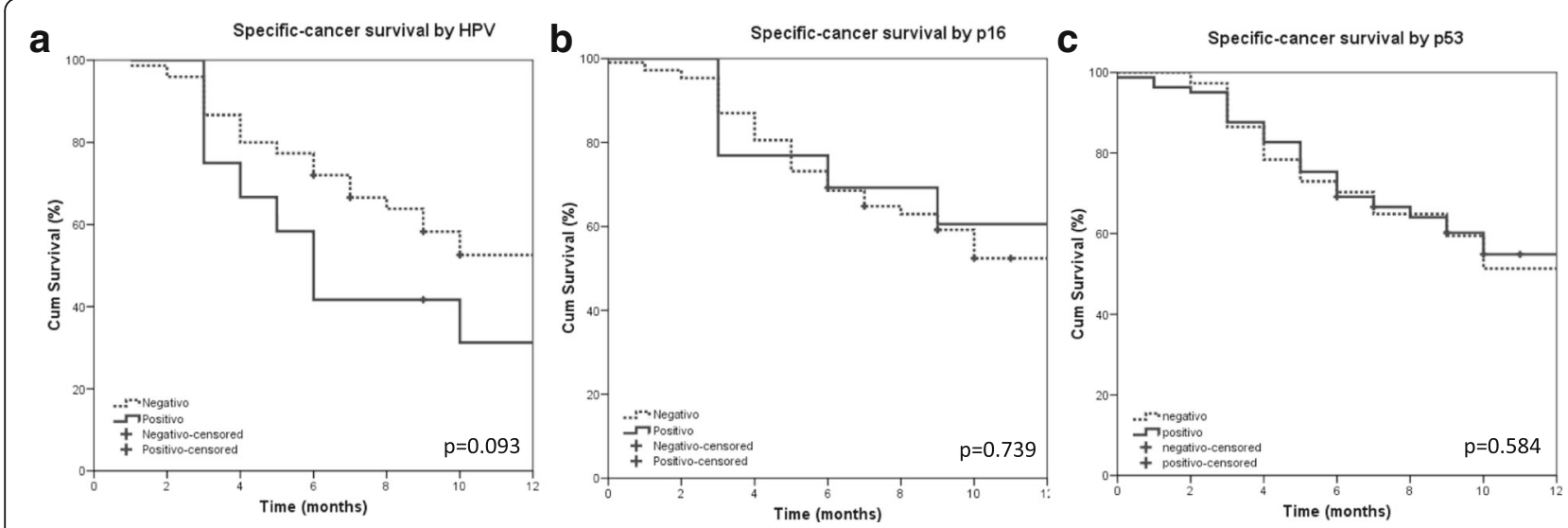

Fig. 1 Kaplan Meier curves for specific-cancer survival according HPV, p53 and p16 status

tumors, but this condition was not associated with overall survival [39]. Recently, Wang et al. (2015) demonstrated that the risk of developing multifocal ESCC was not significantly different between HPV-positive and HPV-negative groups. However, patients with HPV16 infection, specifically, had better response to CRT than those without HPV 16 infection [2].

Different results have also been reported in other studies. Cao et al. (2014) demonstrated that HPV infected patients had better 5-year rates of overall survival and reduction in the risk of death [22]. In contrast, Furihata et al. (1993) reported that HPV positive patients have worse survival than those HPV negative with overexpression of $\mathrm{p} 53$ in EC patients [40].

In addition to investigating HPV infection in EC, our group has also previously assessed the expression of molecular markers p53 and p16, considered to be essential G1 cell cycle regulatory genes whose loss of function is associated with ESCC carcinogenesis [41], and found that the expression of these proteins was significantly higher in tumor tissues compared to adjacent normal tissue to the tumor and also esophageal tissue from individuals without EC [25]. Based on this interesting result, we decided to evaluate the impact of increased expression of these proteins in EC as regards the survival of these patients. We find, through a multivariate analysis, that p53 and p16 expression showed no predictive value for progression-

Table 4 Risk of cancer progression or death according to HPV, p53 and p16 status

\begin{tabular}{|c|c|c|c|c|c|}
\hline \multirow[t]{2}{*}{ Model } & \multirow{2}{*}{$\begin{array}{l}\text { Variable } \\
\text { of interest }^{\mathrm{a}}\end{array}$} & \multicolumn{2}{|c|}{ Progression-free survival } & \multicolumn{2}{|c|}{ Specific-cancer survival } \\
\hline & & $\mathrm{HR}$ & {$\left[\mathrm{Cl}^{95 \%}\right]$} & $\mathrm{HR}$ & {$\left[\mathrm{Cl}^{95 \%}\right]$} \\
\hline 1 & HPV & 1.042 & [0.293: 3.709] & 1.901 & [0.926: 3.900] \\
\hline 2 & p16 & 1.137 & [0.383: 3.378] & 1.268 & [0.617: 2.604] \\
\hline 3 & p53 & 1.318 & [0.646: 2.689] & 1.177 & [0.726: 1.907] \\
\hline
\end{tabular}

${ }^{a}$ Model adjusted by sex. Clinical stage and treatment (surgery and chemoradiotherapy). HR: Hazard ratio free and specific-cancer survival. The results found in literature related to the expression of these markers and survival in ESCC are widely variable.

Currently, there are several studies trying to correlate the expression of $\mathrm{p} 53$ protein and mutations in the p53 gene with survival of patients carrying EC, and the results are widely variable. Bahnassy et al. (2005) and Huang et al. (2014) found that high p53 expression was associated with a poor survival rate in ESCC patients [42, 43]; and Han et al. (2007) showed that p53 expression was positively correlated with tumor stage and lymph node metastasis [44]. Ye et al. (2012) reported that p53 expression was not associated with the gender or age of the patient, but was associated with tumor differentiation degree and lymph node metastasis [45]. A retrospective cohort study of 136 ESCC patients, conducted to investigate the prognostic role of p53 in patients with ESCC suggested that overexpression of this protein was associated with poor prognosis in these patients, and it's a significantly independent predictor of poorer overall survival $(p=0.04)$ [16]. Furthermore, significant associations were also found between high expression of p53 and poor prognosis by Shang et al. (2014), Xu et al. (2014) and Chen et al. (2015), suggesting that this protein is an important biomarker candidate for the prognosis of patients with ESCC [3, 14, 23].

Similarly to our results, Chino et al. (2001) showed that p53 expression was not associated with tumor infiltration deepness, lymph node metastasis, or venous and/or lymphatic invasion [46]. Murata et al. (2013) examined the clinical and prognostic features of p53 immunohistochemical expression in 266 ESCC patients and found that the protein expression has no impact on the prognosis of ESCC, according to them, possibly due to their short follow-up time [47]. Furthermore, a p53 research group study demonstrated that, for EC, p53 immunohistochemistry does not correlate with response to chemotherapy, curative 
resection rate, or prognosis, whereas data from p53 mutation analyses are more consistent concerning the association of p53 mutation and poor survival [48]. These discrepancies may be related to several factors, including small sample sizes, patient selection bias, failure to take into account other prognostic parameters, differences in laboratory techniques (for example, the use of different monoclonal antibodies to screen for p53 expression) and a shorter time of follow-up [16, 47]. To date, the role of this protein in relation to EC patients' survival is not fully understood.

Unlike the large number of findings related to p53 overexpression and survival, studies seeking to correlate p16 expression with EC patient survival are scarce, since the vast majority uses this protein as an indirect marker for HPV infection.

Opposite to our findings, Cao et al. (2014) found that p16-positive patients had better 5-year rates of overall survival and progression free survival than p16-negative group [22] and similarly, Kumar et al. (2015) found that the p16 expression in ESCC correlates with a higher rate of pathologic complete remission in patients submitted to neo adjuvant chemotherapy, and could be considered as a predictive marker for response assessment. Furthermore, moderately differentiated histological grade, surgery, chemotherapy and progression or metastasis have shown their prediction value for specific-cancer survival [21]. However, no significant correlations were found between the proteins expression and clinical outcomes ${ }^{[1515]}$, corroborating our findings.

\section{Conclusions}

HPV status did not statistically correlated to survival rates, despite the clear tendency of positive HPV cases to be more aggressive than the HPV negative, in opposition to HPV significance in oropharyngeal cancers.

\section{Abbreviations \\ Cl: Confidence Interval; CTR: Chemoradiotherapy; EC: Esophageal cancer; ESCC: Esophageal squamous cell carcinoma; HPV: Human papillomavirus;} PCR: Polymerase chain reaction

\section{Acknowledgements}

The authors would like to thank the Barretos Cancer Hospital, HPV Teams at Barretos Cancer Hospital and Molecular Biology Laboratory, Center for Translational Research in Oncology, São Paulo Cancer Institute (ICESP), São Paulo, Brazil. CNPq Universal for providing supplies to the largest study, of which this study is a part of, entitled "The role of human papillomavirus (HPV) as the etiologic agent of esophageal cancer. A cross-sectional study, case-control and longitudinal at Barretos Cancer Hospital"(process: 482666 / 2012-9).

Funding

CNPq Universal for providing supplies to the largest study, of which this study is a part of, entitled "The role of human papillomavirus (HPV) as the etiologic agent of esophageal cancer. A cross-sectional study, case-control and longitudinal at Barretos Cancer Hospital"; (Grant number 482666/2012-9 to ALF); INCT HPV [Fundação de Amparo à Pesquisa do Estado de São Paulo
}

(FAPESP) [Grant number 08/57889-1 to LLV]; Conselho Nacional de Desenvolvimento Científico e Tencnológico (CNPq) (Grant number 573799/ 2008-3 to LLV)].

\section{Availability of data and materials}

Please contact author for data requests.

\section{Authors' contributions}

AMC participated in the conception, design, development of methodology, acquisition of data, analysis and interpretation and writing of the manuscript; JHTGF participated in the conception, design, analysis and interpretation of data and review and revision of the manuscript; PRAP, VSM and EMS participated in the conception, design, development of methodology and acquisition of data; CSN, DPG developed the methodology and reviewed the manuscript; LS and LLV participated in the analysis and interpretation of data and review of the manuscript; KJS and ALF participated the conception, design, writing, review of the manuscript and study supervision. All authors read and approved the final manuscript.

\section{Ethics approval and consent to participate}

This study was approved by the local Ethics Committee under registration number 134471. All patients with limited understanding of research objectives during the consent, with unfavorable clinical conditions for sampling biopsies during endoscopy, previous history of any malignant neoplasia, and inadequate quality of sample were excluded. Patients were referred to a private room and informed about the purpose of the study, procedures for biological sampling and the necessary information requested on the data collection instrument. All patients included on study signed the Informed Consent form.

\section{Consent for publication \\ Not applicable.}

\section{Competing interests}

The authors declare that they have no competing interests.

\section{Publisher's Note}

Springer Nature remains neutral with regard to jurisdictional claims in published maps and institutional affiliations.

\section{Author details}

${ }^{1}$ Teaching and Research Institute, Barretos Cancer Hospital - Pius XII Foundation, Rua Antenor Duarte Vilela, 1331, Dr. Paulo Prata, Barretos, São Paulo 14784-400, Brazil. ${ }^{2}$ Cancer Registry, Barretos Cancer Hospital - Pius XII Foundation, São Paulo, Brazil. ${ }^{3}$ Molecular Oncology Research Center, Barretos Cancer Hospital - Pius XII Foundation, São Paulo, Brazil. ${ }^{4}$ Department of Endoscopy, Barretos Cancer Hospital - Pious XII Foundation, Barretos, São Paulo, Brazil. ${ }^{5}$ Molecular Biology Laboratory, Center for Translational Research in Oncology, Instituto do Câncer do Estado de São Paulo - ICESP, São Paulo, Brazil. ${ }^{6}$ Department of Radiology and Oncology, School of Medicine, University of São Paulo, São Paulo, Brazil. 'Department of Clinical Research Biohit Oyj, Helsinki, Finland. ${ }^{8}$ Medical Laboratory of Medical Investigation (LIM) 14, Department of Pathology, Faculty of Medicine, University of São Paulo, São Paulo, Brazil. ${ }^{9}$ Research Institute of Life and Health Sciences (ICVS), University of Minho, Braga, Portugal. ${ }^{10}$ ICVS / 3B's - Associated Laboratory to the Government of Portugal, Braga/Guimarães, Portugal.

Received: 5 April 2017 Accepted: 5 October 2017

Published online: 13 October 2017

\section{References}

1. GLOBOCAN 2012 v1.0, Cancer Incidence and Mortality Worldwide: IARC CancerBase No. 11 [Internet] [http://globocan.iarc.fr]. Accessed 27 Sept 2017.

2. Wang WL, Wang YC, Lee CT, Chang CY, Lo JL, Kuo YH, Hsu YC, Mo LR. The impact of human papillomavirus infection on the survival and treatment response of patients with esophageal cancers. J Dig Dis. 2015;16:256-63.

3. Chen J, Wu F, Pei HL, Gu WD, Ning ZH, Shao YJ, Huang J. Analysis of the correlation between P53 and Cox-2 expression and prognosis in esophageal cancer. Oncol Lett. 2015;10:2197-203. 
4. Syrjanen K. HPV et tumeurs épidermoïdes bénignes et malignes de l'æsophag. In: PJ AF, Mougin C, editors. Papillomavirus Humains Biologie et pathologie tumorale. Paris: TEC \& DOC; 2003.

5. Syrjanen KJ. HPV infections and oesophageal cancer. J Clin Pathol. 2002;55:721-8.

6. Syrjanen KJ. Human papillomavirus (HPV) infections and their associations with squamous cell neoplasia. Arch Geschwulstforsch. 1987;57:417-44.

7. Syrjänen K, Chang F, Syrjänen S. Infectious agents as etiological factors in esophageal carcinogenesis. In: Tahara E, Sugimachi K, Oohara T, editors. Recent advances in gastroenterological carcinogenesis I. Bologna: Monduzzi Editore; 1996. p. 29-43.

8. Syrjanen K. HPV infections of the oesophagus. In: Papillomavirus infections in human pathology. New York: Wiley \& Sons; 2000. p. 413-28.

9. Syrjanen K. HPV infections in etiology of benign and malignant sinonasal, bronchial and oesophageal squamous cell lesions. In: 4th International Multidisciplinary Congress EUROGIN (Monsonego J ed. Pp. 169-179). Bolongna: Monduzzi Editore; 2000. p. 169-79.

10. Syrjanen K, Pyrhonen S, Aukee S, Koskela E. Squamous cell papilloma of the esophagus: a tumour probably caused by human papilloma virus (HPV). Diagn Histopathol. 1982;5:291-6.

11. Syrjanen KJ. Histological changes identical to those of condylomatous lesions found in esophageal squamous cell carcinomas. Arch Geschwulstforsch. 1982:52:283-92.

12. Kamangar F, Chow WH, Abnet CC, Dawsey SM. Environmental causes of esophageal cancer. Gastroenterol Clin N Am. 2009:38:27-57. vii

13. Antunes LC, Prolla JC, de Barros LA, da Rocha MP, Fagundes RB. No evidence of HPV DNA in esophageal squamous cell carcinoma in a population of southern Brazil. World J Gastroenterol. 2013;19:6598-603.

14. Shang L, Liu HJ, Hao JJ, Jiang YY, Shi F, Zhang Y, Cai Y, Xu X, Jia XM, Zhan QM, Wang MR. A panel of overexpressed proteins for prognosis in esophageal squamous cell carcinoma. PLoS One. 2014;9:e111045.

15. Shibata-Kobayashi S, Yamashita H, Okuma K, Shiraishi K, Igaki H, Ohtomo K, Nakagawa K. Correlation among 16 biological factors [p53, p21(waf1), MIB-1 (Ki-67), p16(INK4A), cyclin D1, E-cadherin, Bcl-2, TNF-alpha, NF-kappaB, TGFbeta, MMP-7, COX-2, EGFR, HER2/neu, ER, and HIF-1alpha] and clinical outcomes following curative chemoradiation therapy in 10 patients with esophageal squamous cell carcinoma. Oncol Lett. 2013;5:903-10.

16. Yao W, Qin X, Qi B, Lu J, Guo L, Liu F, Liu S, Zhao B. Association of p53 expression with prognosis in patients with esophageal squamous cell carcinoma. Int J Clin Exp Pathol. 2014;7:7158-63.

17. Chang F, Syrjanen S, Syrjanen K. Implications of the p53 tumor-suppressor gene in clinical oncology. J Clin Oncol. 1995;13:1009-22.

18. Lassen P, Eriksen JG, Hamilton-Dutoit S, Tramm T, Alsner J, Overgaard J. Effect of HPV-associated p16INK4A expression on response to radiotherapy and survival in squamous cell carcinoma of the head and neck. J Clin Oncol. 2009;27:1992-8.

19. Sturm I, Petrowsky H, Volz R, Lorenz M, Radetzki S, Hillebrand T, Wolff G, Hauptmann S, Dorken B, Daniel PT. Analysis of p53/BAX/p16(ink4a/CDKN2) in esophageal squamous cell carcinoma: high BAX and p16(ink4a/CDKN2) identifies patients with good prognosis. J Clin Oncol. 2001;19:2272-81.

20. Cao F, Han H, Zhang F, Wang B, Ma W, Wang Y, Sun G, Shi M, Ren Y, Cheng Y. HPV infection in esophageal squamous cell carcinoma and its relationship to the prognosis of patients in northern China. ScientificWorld Journal. 2014;2014:804738.

21. Kumar R, Ghosh SK, Verma AK, Talukdar A, Deka MK, Wagh M, Bahar HM, Tapkire R, Chakraborty KP, Kannan RR. p16 expression as a surrogate marker for HPV infection in esophageal Squamous cell carcinoma can predict response to neo-adjuvant chemotherapy. Asian Pac J Cancer Prev. 2015;16:7161-5.

22. Cao F, Zhang W, Zhang F, Han H, Xu J, Cheng Y. Prognostic significance of high-risk human papillomavirus and p16(INK4A) in patients with esophageal squamous cell carcinoma. Int J Clin Exp Med. 2014;7:3430-8.

23. Xu XL. Zheng WH, Tao KY, Li XX, Xu WZ, Wang Y, Zhu SM, Mao WM: p53 is an independent prognostic factor in operable esophageal squamous cell carcinoma: a large-scale study with a long follow-up. Med Oncol. 2014;31:257.

24. Green MR, Sambrook J. Molecular Cloning: A Laboratory Manual, 4thed. New York: John Inglis N; 2012.

25. Pastrez PRA, Mariano VS, da Costa AM, Silva EM, Scapulatempo-Neto C, Guimaraes DP, Fava G, Neto SAZ, Nunes EM, Sichero L, et al. The relation of HPV infection and expression of p53 and p16 proteins in esophageal Squamous cells carcinoma. J Cancer. 2017;8:1062-70.
26. da Costa AM, Fregnani J, Pastrez PRA, Mariano VS, Neto CS, Guimaraes DP de Oliveira KMG, Neto SAZ, Nunes EM, Ferreira S, et al. Prevalence of high risk HPV DNA in esophagus is high in Brazil but not related to esophageal squamous cell carcinoma. Histol Histopathol. 2017;11929

27. Schmitt M, Bravo IG, Snijders PJ, Gissmann L, Pawlita M, Waterboer T. Beadbased multiplex genotyping of human papillomaviruses. J Clin Microbiol. 2006;44:504-12.

28. World Health Organization. Genital human papillomavirus infections and cancer: memorandum from a WHO meeting. Bull World Health Organ. 1987; 65:817-27.

29. Shen ZY, Xu LY, Li EM, Shen J, Zheng RM, Cai WJ, Zeng Y. Immortal phenotype of the esophageal epithelial cells in the process of immortalization. Int J Mol Med. 2002;10:641-6.

30. Cervantes J. Update on the pathogenesis and immunotherapy of esophageal squamous cell carcinoma. Rev Gastroenterol Peru. 2004;24:165-70.

31. Tao CJ, Lin G, Xu YP, Mao WM. Predicting the response of Neoadjuvant therapy for patients with esophageal carcinoma: an in-depth literature review. J Cancer. 2015;6:1179-86.

32. Weinberger PM, Yu Z, Haffty BG, Kowalski D, Harigopal M, Brandsma J, Sasaki C, Joe J, Camp RL, Rimm DL, Psyrri A. Molecular classification identifies a subset of human papillomavirus-associated oropharyngeal cancers with favorable prognosis. J Clin Oncol. 2006;24:736-47.

33. Fakhry C, Westra WH, Li S, Cmelak A, Ridge JA, Pinto H, Forastiere A, Gillison ML. Improved survival of patients with human papillomavirus-positive head and neck squamous cell carcinoma in a prospective clinical trial. J Natl Cancer Inst. 2008;100:261-9.

34. Ang KK, Harris J, Wheeler R, Weber R, Rosenthal DI, Nguyen-Tan PF, Westra WH, Chung CH, Jordan RC, Lu C, et al. Human papillomavirus and survival of patients with oropharyngeal cancer. N Engl J Med. 2010;363:24-35.

35. Dreilich M, Bergqvist M, Moberg M, Brattstrom D, Gustavsson I, Bergstrom S, Wanders A, Hesselius P, Wagenius G, Gyllensten U. High-risk human papilloma virus (HPV) and survival in patients with esophageal carcinoma: a pilot study. BMC Cancer. 2006;6:94.

36. Skinner SR, Apter D, De Carvalho N, Harper DM, Konno R, Paavonen J, Romanowski B, Roteli-Martins C, Burlet N, Mihalyi A, Struyf F. Human papillomavirus (HPV)-16/18 AS04-adjuvanted vaccine for the prevention of cervical cancer and HPV-related diseases. Expert Rev Vaccines. 2016;15:367-87.

37. Liu WK, Jiang XY, Zhang MP, Zhang ZX. The relationship between HPV16 and expression of cyclooxygenase-2, P53 and their prognostic roles in esophageal squamous cell carcinoma. Eur J Gastroenterol Hepatol. 2010;22:67-74.

38. Hippelainen M, Eskelinen M, Lipponen P, Chang F, Syrjanen K. Mitotic activity index, volume corrected mitotic index and human papilloma-virus suggestive morphology are not prognostic factors in carcinoma of the oesophagus. Anticancer Res. 1993:13:677-81.

39. Herbster S, Ferraro CT, Koff NK, Rossini A, Kruel CD, Andreollo NA, Rapozo DC, Blanco TC, Faria PA, Santos PT, et al. HPV infection in Brazilian patients with esophageal squamous cell carcinoma: interpopulational differences, lack of correlation with surrogate markers and clinicopathological parameters. Cancer Lett. 2012;326:52-8.

40. Furihata M, Ohtsuki Y, Ogoshi S, Takahashi A, Tamiya T, Ogata T. Prognostic significance of human papillomavirus genomes (type-16, -18) and aberrant expression of p53 protein in human esophageal cancer. Int J Cancer. 1993:54:226-30

41. Taghavi N, Biramijamal F, Sotoudeh M, Moaven O, Khademi $H$, Abbaszadegan MR, Malekzadeh R. Association of p53/p21 expression with cigarette smoking and prognosis in esophageal squamous cell carcinoma patients. World J Gastroenterol. 2010;16:4958-67.

42. Bahnassy AA, Zekri AR, Abdallah S, El-Shehaby AM, Sherif GM. Human papillomavirus infection in Egyptian esophageal carcinoma: correlation with p53, p21, mdm2, C-erbB2 and impact on survival. Pathol Int. 2005;55:53-62.

43. Huang K, Chen L, Zhang J, Wu Z, Lan L, Wang L, Lu B, Liu Y. Elevated p53 expression levels correlate with tumor progression and poor prognosis in patients exhibiting esophageal squamous cell carcinoma. Oncol Lett. 2014:8:1441-6.

44. Han U, Can OI, Han S, Kayhan B, Onal BU. Expressions of p53, VEGF C, p21: could they be used in preoperative evaluation of lymph node metastasis of esophageal squamous cell carcinoma? Dis Esophagus. 2007:20:379-85

45. Ye B, Wang X, Yang Z, Sun Z, Zhang R, Hu Y, Lu Y, Du J. p53 and p73 expression in esophageal carcinoma correlate with clinicopathology of tumors. Hepato-Gastroenterology. 2012;59:2192-5. 
46. Chino O, Kijima H, Shimada H, Nishi T, Tanaka H, Kise Y, Kenmochi T, Himeno S, Machimura T, Tanaka M, et al. Accumulation of p53 in esophageal squamous cell carcinoma. Int J Mol Med. 2001;8:359-63.

47. Murata A, Baba Y, Watanabe M, Shigaki H, Miyake K, Karashima R, Imamura Y, Ida S, Ishimoto T, Iwagami S, et al. p53 immunohistochemical expression and patient prognosis in esophageal squamous cell carcinoma. Med Oncol. 2013;30:728.

48. Kandioler D, Schoppmann SF, Zwrtek R, Kappel S, Wolf B, Mittllbock M, Kuhrer I, Hejna M, Pluschnig U, Ba-Ssalamah A, et al. The biomarker TP53 divides patients with neoadjuvantly treated esophageal cancer into 2 subgroups with markedly different outcomes. A p53 research group study. J Thorac Cardiovasc Surg. 2014;148:2280-6.

Submit your next manuscript to BioMed Central and we will help you at every step:

- We accept pre-submission inquiries

- Our selector tool helps you to find the most relevant journal

- We provide round the clock customer support

- Convenient online submission

- Thorough peer review

- Inclusion in PubMed and all major indexing services

- Maximum visibility for your research

Submit your manuscript at www.biomedcentral.com/submit
Biomed Central 